\title{
Critical Exploration of Counselor Client Relationship in Disability and Gender -Case Study
}

\author{
Arpita Ghosal* \\ Department of Psychology, White lands Collage, London
}

Received: 海 August 23, 2018; Published: 㭗 August 31, 2018

*Corresponding author: Arpita Ghosal, Department of Psychology, University of Roehampton, White lands Collage, Holybourne Ave, London SW15 4JD

\section{Abstract}

This study examines the working experiences of the counselors and their relationship with their clients. There are two types of clients chosen for this study: clients with intellectual disability and the clients of opposite gender. A critical analysis has been carried out with regards to the two types of clients and their relationship with the therapist. I have taken some interviews that have been stated in the paper. Some real cases have also been used to explain the aspects of counselor's relationship with the clients.

\section{Introduction}

The purpose of this essay is to focus on 2 topics: disability and gender and what these mean with regards to the counselors working with clients.

\section{Intellectual Disability}

Disability has been generically neglected in the field of counseling [1] and intellectual disability has been marginal for the marginalized. There are examples of good work done by the counselors with client group, although the activities are mostly on the fringe. It began in 1970s when advocacy groups of disabled people have shown adults having learning difficulties can understand their situation, can have voice and can communicate. It has been noted that the number of intelligent "intellectually disabled" people now is more than their numbers 20 years ago. Even today, it is assumed that an intellectual disabled person does not have the ability of using counseling and superhuman skills are required by the therapist.

As a matter of fact, the counseling has nothing unique to the people with mild learning difficulties. Nevertheless, many people with this label avoid being counseled, when they may have the ability of counseling other individuals, of equal ability, to the ones not bearing the label. There should not be any assumption that counseling must be long term. Even a single session can have productiveness to the client. As adults having learning difficulties are faced often with negativity in large scale. The approaches that are less likely in doing further harm to the self-esteem of such client is emphasizing potential, positives and strengths [2].

This client group is thoroughly disempowered making respect and empowerment crucial for them (Oliver, 1995), specially the clients incapable of defending themselves against intrusive and unwelcome questions [3].

\section{Case}

Jane, since childhood has been labeled with ID (intellectual disability). John is her husband who has also attended special school, but ID was not labeled against him. For years, the family had service involvement and has been a family with multi-problems. They had one child, who due to alleged neglect has been removed. The psychologist's report and the Protective Service reports clearly said that the mother failed to learn in altering her parenting in any way that is significant. However, after seeing this family, these negative assumptions were not believable.

A major issue to counsel this family was lack of the consistent discipline and boundaries. This been a problem that is quite common to parents with learning difficulties. After a discussion with the family, it was concluded that John has given about 10 percent time to the demanding behavior and tantrums of their children, while Jane has given about 50 percent of her time. It should be noted here that without the discussion with them neither would have admitted of the time given by them. However, on further discussion, the estimates of the couple showed that the time given by Jane decreased steadily till John admitted shamefacedly that he gave more time than her. On the other hand, there was complaint from their daughter that she it was getting very difficult for her 
to get things her own way. The tantrums of their daughter were reduced from daily to fortnightly.

It is necessary for the counselors of being beware of the assumption that feelings, attitudes or behavior are not caused by disability. Disabilities can be influencing, although it ceases to cause behavior. One strongly tends to assume a lacking understanding or skill causes difficulty, where the real cause may be lack of experience, lack of motivation or emotional factors. This makes it easier for the counselors to counsel clients as changing motivation and removing emotional blocks are easier than improving problem solving ability or teaching skills.

\section{Communication and Counseling Style}

The style of communication of the clients with mild learning difficulties varies from articulate to monosyllabic. The IQ in most cases, tells nothing useful about the capacities of an individual as two people having identical IQ can be varying greatly in terms of practical ability such as verbal fluency. Vocabulary as a guide to measure the understanding level of an individual can also be very misleading [3]. The counselors constantly need to check their language as well as how well the client understands them. Only simplifying is not enough. The key is the sensitivity and to aim too low or to treat the clients as a child can be considered as more damaging in counseling session than to say things that sometimes cannot be comprehended by the clients. The counselors with clients having learning difficulties usually need slowing down, both in their speed and communication with which the proceedings of the therapy take place. This should depend wholly on the individual client and its application is equally relevant to clients without learning difficulties. The counselors need to be active in their approach of counseling. A counseling style that is passive and reflective is not going to get very far. The counseling styles relying on indirect statements or complex questions can be confusing. However, it is not likely that there can be any counseling approach which cannot be adapted. The counselors, on occasions, may need giving more direct guidance and advice than they generally do. This, however, carries the risk of being overtly controlling or directive.

The counselors also need supplying words in helping a client explaining herself. Words such as 'depression, 'stress', and 'frustration' can be used and explained. This not only will be assisting the communication, but also be normalizing. However, the counselors should be bearing of sets of responses. For example, when the clients say 'yes' to most questions, it can construe that they have not understood the questions [4]. This may also be the strategies of clients with disabilities to hide their limitations and be accepted in the society [5].

\section{Abuse, Harassment, and Discrimination}

The counselors need to be sensitive to the people with intellectual disability with experiences of victimhood. Most of the mildly intellectually disabled people have been harassed or abused at some point in their lives [6]. This takes place within the family or wider community and even in their workplaces by clients and colleagues. In such a scenario, a strength/solution approach can reduce the guilt and shame of the client and help restoring dignity of the individuals being dehumanized.

\section{Risk Assuming Lack of Understanding Case}

Lucy was the single mother of her ten-year-old son who had been verbally abusing and hitting her when at home. He was been placed in foster care recently. She got the access of visiting him and their relationship was improving steadily. Both Lucy and her son agreed they were not ready for him returning home. In the Children's Court, when Lucy's barrister asked if she wants her son back home, she affirmed. When the barrister again asked whether she wanted to contest the matter, her answer was affirmative too. Lucy was less socially competent and articulate person than even the individuals with mild learning difficulties. The initial reaction of her counselor to this incident had been that she could not understand the language of the barrister.

When Lucy's counselor discussed further on the matter with her, it was found that she understood the implication of the contested hearing, but she was terrified of courts. Counselor then asked her whether she felt guilty of not fighting to get her son back home. This question was made based on a hunch that was based on the experience of dealing with the non-disabled single mothers that have lost their children's custody. The answer to this question was a vigorous yes from Lucy. She then said that she wanted her son to be in the foster care if his behavior not becoming normal. The counselor appreciated her decisions and told her that it was an admirable and normal decision. What was found out from this case is that people with learning difficulties have the identical emotions as rest of the people. It can be concluded here that individuals (especially children, the less educated, the elderly, non-English speakers, and people with disabilities and mental illness) understand more than their ability of demonstrating or communicating them.

\section{Gender}

The aspect of gender issue in counseling that will be discussed in this paper is the experience of the women counselors who works with the male clients. The focus would remain in exploring the understanding of women in relation to their work with men. I have tried to determine the meaning that is given by the participants (people I have taken interview of) to their work. In other words, what the participants assume in making about male female relationship, and what significance they extend in the gender difference within the scope of counseling relationship. With respect the conflicts women counselors face with their male clients, the social construction of gender within the society influencing 
the women's work in counseling with men where women need understanding of those construction's limitations.

Both men and women are parts of patriarchal structure that determines the structure of women and men socialization. The gender stereotyping has been challenged by the feminists and how it silences women and the maintenance of inequality between women and men. The men's studies, on the other hand, has highlighted the oppression of women under patriarchy, but has also identified how under such a system man have also suffered.There have been authors that have argued whether the advantages of men counseling men are more than women counseling men. It is without doubt that majority of therapy professionals and social workers are women. Therefore, it is inevitable that women will be treating male clients. Thus, the assumption that same sex counseling should be the norm is misguided and unrealistic [7].

There is opportunity for the women counselors in helping men having a different experience of female and male relationships. The women counselors can challenge the sexist attitude of men towards women and, they have the opportunity of talking to men regarding their feelings [8]. Feminists have started recognizing the need of working with men in understanding the male power's complexity. Scully suggests that the accomplishment of debunking patriarchy cannot be achieved by the exclusive focus on the experiences and lives of women [9].With the growth of the study pertaining to the gender relationship in therapy, there has been increased recognition that men are viewed as psychologically vulnerable and oppressors [10].

It is also suggestive that counseling relationship extends men with a model that allows them in having a different experience with a woman that can be integrated into their personal relationships [7]. However, this position's pitfall in assuming that female counselors are conscious of gender relations can offer men with a different understanding regarding male/female relationships. There should be awareness of the women counselors about their "blind spots" as they work with men. Unless the women counselors have the awareness of their own beliefs and issues regarding gender socialization, the risk remains for them with regards to the perpetuating traditional attitudes that are harmful to both women and men. The question of how women counselors should be working with men should replace why women should be working with men [11]. It should not be seen that counselor and the client are engaged a personal struggle, but the understanding of the relationship must be in a larger context. However, the counselor and the client negotiate at the individual level which can be considered as very political issue: the relationship between men and women. The poststructuralist and feminist writers have helped me comprehending that what has been considered as "reality" or "norm" cannot be depicted as an objective certainty.

\section{Difficulty Trusting Male Client}

The biases, beliefs, and attitudes are brought about by women counselors in their work. These are part of their personal history and socialization. However, there is should also be consideration of the problem of trust by understanding that counseling has the intension of helping people in learning more about themselves and finding ways of dealing with the problems. Here, an assumption is taken as to when clients expresses their feelings in words and revealing themselves to the counselor, there will be development of a trusting relationship. The male clients often find it difficult in expressing their feelings or trusting their feelings to a counselor. There are some female counselors, interviewed by me, believed that they being women further limited the willingness of men in trusting their feelings to the counselors. This is especially true in situations when men come talking about the problems they face in their relationships with women. Mary, a counselor I interviewed, explains that this problem emerged with two clients whose "partners has abandoned them and ended the relationship". Mary further said, "Their anger towards their wives went overboard and became a cause of non-acceptance of me and the counseling I tried to do. They thought I am siding with the woman when I gently raised the issue that change was necessary even on their part with regards to their behavior. One male client told me that female counselors don't understand their point of view and are not in their best interest.

\section{Sexuality}

The sense that sexuality is a problem of men has been formulated by a counselor, who was also interviewed. She talked about a client who had severe mental health problems buttressed by his sexual behavior. The female counselor perceived a dark side to him and led to the client being referred to a male counselor. She explained: "he talked about the breakdown of his marriage and the distress accompanying such an incident. But when I started peeling back the layers, I found some brown layers there. He started describing that he has put ads in the personal column and the response he got from the women and how he related with those women. I felt he had some sociopathic kind of an underlying component, for which he should see a male counselor. Also, I did not have any perspective on the kind of things he was doing".

\section{Cognitive Approaches in Counseling}

My experience with other female counselors is suggestive that they mostly used cognitive behavioral or problem-solving interventions on gender issues. Mary, a counselor I interviewed said that she used relational model with women, but with men her work was different. She said, "I have done a lot of relational work with female clients although I feel with male clients this approach is not appropriate. With male clients I generally do with more cognitive behavioral orientation". It must be emphasized here that 
often men come to women counselors for depression related to marital breakup. The men clients usually have little interest in the understanding related to reason of such breakup. They want quick answers in relieving their pain.

\section{Conclusion}

This paper examined intellectual disability and gender in relation to relational equation between the client and the counselors. In the case of intellectual disability, confusion surrounds the concept and the stigma attached to this label. Counseling with respect to mild intellectual disability is very much neglected. The aspects of counseling relationship between the counselor and the client with respect to the intellectual disability are communication and counseling style, lacking understanding, abuse, harassment, and discrimination. With regards to gender, the focus has been the experience of women counselors working with male clients. It is seen that an important part is played by the gender in counseling shaping the relationship between the counselors and the clients. The communication of the gender has impacted the counseling practice and the need of renegotiation of those communication aspects constricting the relationship between counselors and clients of opposite genders.

\section{References}

1. Hastings E (1997) Hidden Disability Discrimination. Dulwich Centre Newsletter 4: 8-11.

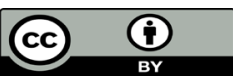

To Submit Your Article Click Here: Submit Article

DOI: $10.32474 /$ PRJFGS.2018.02.000131
2. Russo R (1999) Applying a Strengths-based Practice Approach in Working with People with Developmental Disabilities and their Families. Families in Society: The Journal of Contemporary Human Services 80(1): 5-33.

3. Booth T, Booth W (1998) Growing up with Parents who have Learning Difficulties. London, Routledge.

4. Sigelman C, Budd E, Spenhel C, Schoenrock C (1981) When in Doubt, Say Yes: Acquiescence in Interviews with Mentally Retarded Persons. Mental Retardation 19(2): 53-58.

5. Edgerton R (1967) Mental Retardation. Cambridge, MA, Harvard University Press.

6. McCarthy M I (2000) Consent, Abuse and Choices. In R Traustadottir, K Johnson (Eds.), Women with Intellectual Disabilities, London, Jessica Kingsley.

7. Erickson B (1993) Helping Men Change: the role of the female therapist. Newbury Park: Sage.

8. Forster J (1996) Helping men to cope with marital breakdown. In K Cavanagh and VE Cree (Eds.), Working; with Men: Feminism and Social Work. New York: Routledge pp. 113- 125.

9. Cree VE (1996) Why do men care? In K Cavanagh, VE Cree (Eds.), Working with Men: Feminism and Social Work. New York: Routledge.

10. Brooks G (1991) Traditional Men in Marital and Family Therapy. In M Bograd (Ed.), Feminist Approaches for Men in Family Therapy. New York: Harrington Park Press 2(3-4): 51-74.

11. Cavanagh K, Cree VE (1 996) Working with Men: Feminism and Social Work. New York: Routledge.

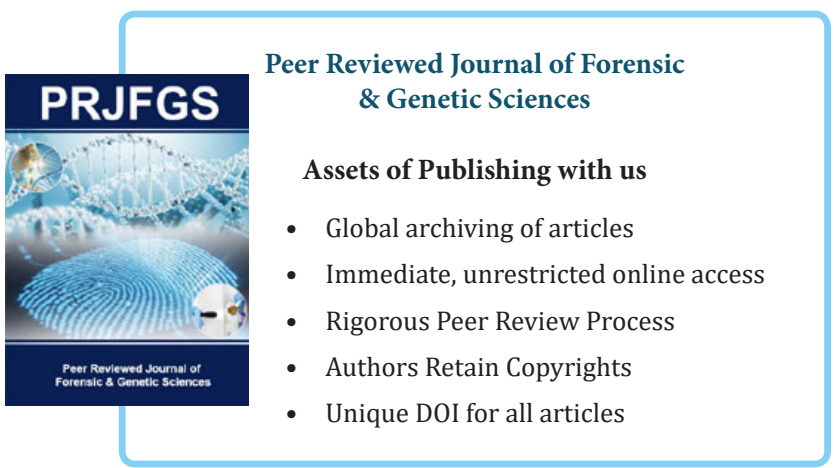

